\title{
Extended effect after a single dose of type A botulinum toxin for asymmetric masseter muscle hypertrophy
}

\author{
Kasturi Bhattacharjee, Manpreet Singh, Harsha Bhattacharjee \\ Department of Orbit and Ophthalmic Plastic and Reconstructive Surgery, Sri Sankaradeva Nethralaya, Beltola, Guwahati, \\ Assam, India
}

Address for correspondence: Dr. Kasturi Bhattacharjee, Department of Orbit and Ophthalmic Plastic and Reconstructive Surgery, Sri Sankaradeva Nethralaya, Beltola, Guwahati - 781 028, Assam, India. E-mail: kasturibhattacharjee44@hotmail.com

\section{ABSTRACT}

Facial asymmetry can either be physiological or pathological and is a common cosmetic concern. A 35-year-old Indian male presented with broad appearing lower face and prominent left jaw since adolescence. Parotid enlargement and other local disorders were ruled out. Ultrasonographic thickness of right masseter muscle was $13 \mathrm{~mm}$ while that of left was $14.9 \mathrm{~mm}$, in unclenched state. Type-A botulinum toxin (T-ABT) was injected, evenly at five points, in both muscles within the "safe zone". Using a 29 gauge needle, 15 and 25 international units were delivered to right and left masseters, respectively. Six months post - injection, a reduction of $2.9 \mathrm{~mm}$ and $4.4 \mathrm{~mm}$ was observed along with a reduced external facial asymmetry. At 24 months, patient maintains a satisfactory facial contour with no significant early or late post-injection complications. Intramassteric injection of T-ABT can be used effectively as a primary or adjunct procedure for holistic oculo-facial sculpting.

\section{KEY WORDS}

Botulinum toxin; extended volume reduction; facial asymmetry; masseter hypertrophy

\section{INTRODUCTION}

sians have a wider lower-third face than Caucasians, which generally is less acceptable to females. This can be secondary to the bony configuration or soft tissue enlargement (masseter muscle hypertrophy, parotid gland enlargement, etc.). Masseteric hypertrophy is a benign condition first described in 1880. ${ }^{[1]}$ Many medical (systemic muscle relaxants) and surgical (muscle resection and modelling

\begin{tabular}{|l|l|}
\hline \multicolumn{2}{|c|}{ Access this article online } \\
\hline Quick Response Code: & Website: \\
\hline & www.ijps.org \\
\cline { 2 - 2 } & Dol: \\
\hline
\end{tabular}

ostectomy) treatment options have evolved for its management. Various side-effects of medications and unpredictable results/ complications of surgery have reduced the demand for treatment. ${ }^{[2]}$

Moore and Wood used type-A botulinum toxin (T-ABT) injection for functional management of masseter

\footnotetext{
This is an open access article distributed under the terms of the Creative Commons Attribution-NonCommercial-ShareAlike 3.0 License, which allows others to remix, tweak, and build upon the work non-commercially, as long as the author is credited and the new creations are licensed under the identical terms.
}

For reprints contact: reprints@medknow.com

How to cite this article: Bhattacharjee K, Singh M, Bhattacharjee $\mathrm{H}$. Extended effect after a single dose of type A botulinum toxin for asymmetric masseter muscle hypertrophy. Indian J Plast Surg 2015;48:196-9. 
hypertrophy. This eventually led Rijsdijk et al., to its cosmetic use for muscle hypertrophy. ${ }^{[1,3]}$ Gradually, botulinum toxin was used frequently due to its predictable results as compared to systemic medications and surgery. Most important limitation for botulinum toxin is its temporary effect for every condition. We report the extended effect of T-ABT single injection for asymmetric masseter hypertrophy in a male patient.

\section{CASE REPORT}

A 35 -year -old Indian male presented to our oculofacial aesthetics clinic with a bulky appearing lower face since his adolescence. He was not having any other ocular and periocular complaint. He had not received botulinum toxin treatment previously for the same condition. There was no history of local trauma or surgery. There was no history of any mental stress or bruxism reported by family members. He had normal eating habits (no habitual tobacco/betel-nut, chewing-gum or hard food chewing). On facial inspection, the lower-third of face, specifically mandibular angle region appeared to be prominent on left side [Figure 1]. On teeth clenching, bilateral masseter muscle became prominent which on palpation appeared as localised single longitudinal bulge, that is, type II hypertrophy according to the Xie's classification. No additional findings were detected on inspection or palpation. His oral and dental examinations were within normal limits. The jaw movements (forward, sideways, and mastication) were confirmed to be normal and the magnitude with dimensions of smile was recorded as clinical pictures.

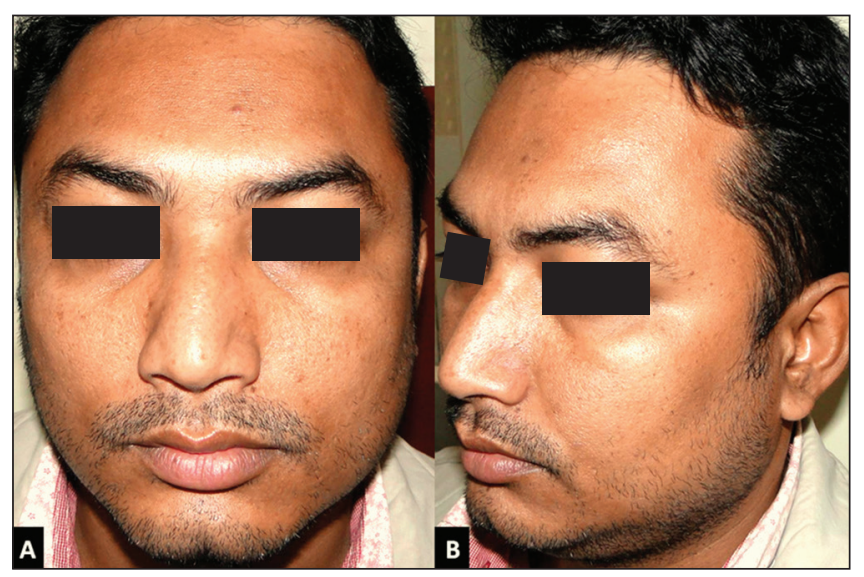

Figure 1: Before botulinum toxin injection, (A) (Front view, without clenching teeth) gross asymmetric lower face with prominence in masseteric region suggestive of masseter hypertrophy, (B) (Oblique view, with clenched teeth) left sided masseteric region showing prominent muscle with local single longitudinal bulge (Xie's type II)
B-scan ultrasonography (USG) $(8 \mathrm{M} \mathrm{Hz})$ was performed for objective measurement of both masseter muscles and to rule out any occult or unsuspected local pathology (parotid enlargement). In unclenched state, right masseter muscle thickness was $13 \mathrm{~mm}$ while that of left was $14.9 \mathrm{~mm}$ (asymmetry $-1.9 \mathrm{~mm}$ ) [Figure 2]. Intramuscular T-ABT was planned for both masseters after explaining the temporary effect and need for re-treatment to the patient. The "safe zone" for intramuscular injection was marked between the upper limit defined by a line joining the tragus and angle of mouth while anterior and posterior borders of masseter were highlighted in clenched state [Figure 3]. This "safe zone" has no anatomically vital structures hence lesser chances for related complications. Freshly prepared T-ABT was injected into the thickest part of each muscle in a diamond shape, equally at five points. The dose was titrated according to the muscle thickness, that is, 15 and 25 international units (IU) into right and left muscle. The patient was kept under observation for $30 \mathrm{~min}$ after injection, to monitor for any adverse reactions.

On follow-up, the ultrasound was repeated to detect the muscle thickness. At 6 months, USG showed a reduction of $2.9 \mathrm{~mm}$ and $4.4 \mathrm{~mm}$ in the right and left masseter muscles, respectively [Figure 2]. There was a prominent effect on asymmetry too, as it reduced from $1.9 \mathrm{~mm}$ to $0.4 \mathrm{~mm}$. There were no significant side-effects (abnormal mastication or paradoxical bulging) in early or late post -injection period. At 24 months of followup, the patient was satisfied with the maintained symmetrical facial appearance as the outcome [Figure 4]. The USG at last follow-up shows asymmetry of $0.2 \mathrm{~mm}$.

\section{DISCUSSION}

The dosage regimen and duration of effect of T-ABT for masseter hypertrophy has yet not been standardised..$^{[4]}$ In

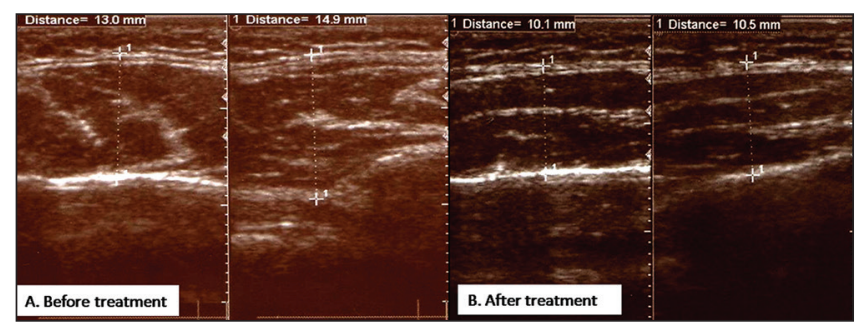

Figure 2: Ultrasound B-scan pictures with calliper markings, (A) At the most prominent part, the right masseter muscle is $13 \mathrm{~mm}$ in thickness while the left muscle is $14.9 \mathrm{~mm}$ thick, (B) The right and left masseter muscles are reduced to $10.1 \mathrm{~mm}$ and $10.5 \mathrm{~mm}$, respectively, signifying the achievement of symmetry on both sides 


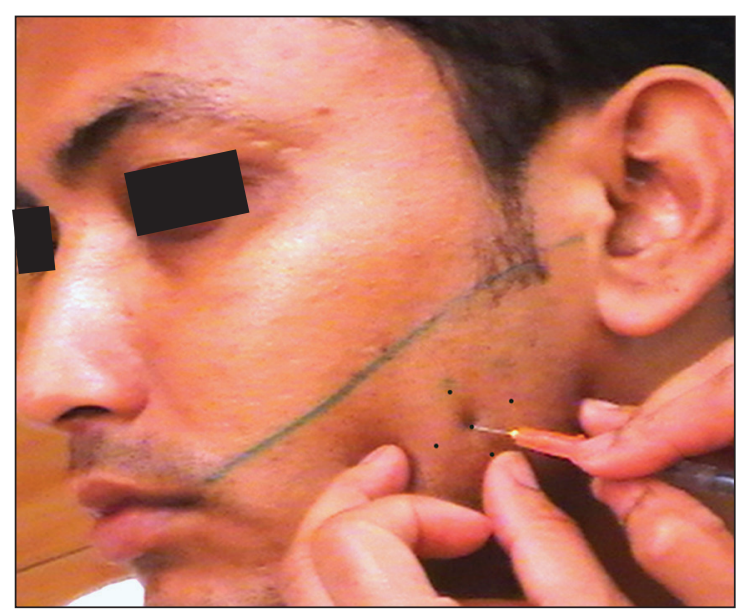

Figure 3: Defining the "safe zone" marking for the masseter muscle. The superior border of muscle is marked by green line, the anterior border being palpated with middle finger of left hand while 29 gauge needle being used to inject the toxin at its most prominent region in a diamond shape (marks shown as dots)

2005, Kim et al. recommended 100- 140 units of Dysport (Ipsen Ltd, Slough, United Kingdom) for 10- $16 \mathrm{~mm}$ thickness while Choe et al. suggested using $>20 \mathrm{IU}$ of Botox (Allergan, Inc., Irvine, California) for any thickness $>10 \mathrm{~mm} \cdot{ }^{[1,5]}$ Recently, Xie et al. classified the masseter hypertrophy and tailored the dose of T-ABT for defining the number, dosage, effect, and complications of the drug. ${ }^{[6]}$ Overall, the literature suggests 20-50 IU of $\mathrm{T}-\mathrm{ABT} /$ muscle for treating the masseteric hypertrophy. ${ }^{[6]}$ Following T-ABT, most patients experience the reduction in muscle mass (atrophic effect) at 2-4 weeks with an average reduction being $31 \%$ of muscle thickness. ${ }^{[4]}$ However, the duration of toxin effect varies individually, hence not predictable.

The effect of T-ABT appears as reduction in the power of muscle contraction, muscle tone, and later-on reduced muscle volume which can be measured with the help of electromyography, USG, computed tomography, and three-dimensional scanning. ${ }^{[7]}$ The induction of this effect follows two stages - "tension reduction" followed by "volume reduction" and the recovery also respects this evolution, that is, "tension recovery" followed by "volume recovery". ${ }^{[4]}$ The anatomical and cosmetic effect of toxin can be well-documented by ultrasound and patient's clinical pictures with the help of critical software based analysis, before and after treatment. ${ }^{[1,5,7]}$

Anatomically, masseter muscle fibres lie in layered fashion, which are innervated by separate nerve bundles. This advocates its particular contraction characteristics

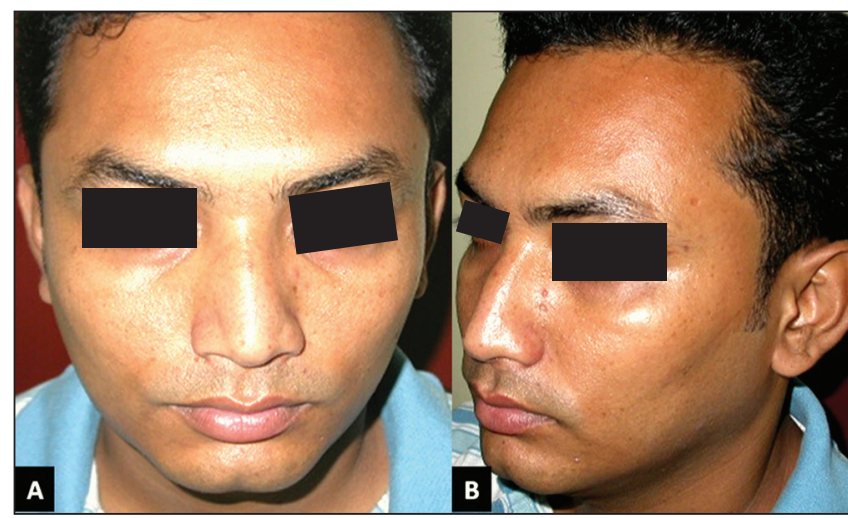

Figure 4: 24 months follow-up, (A) (Front view, without clenching teeth) lower face appears less broad secondary to reduced thickness of masseter muscle, (b) (Oblique view with clenched teeth) left sided view of masseteric region showing flatter masseter muscle without the bulge and less bulkier appearance of mandibular region

and supports the wider distribution of toxin. The multiple injection points ensure homogenous drug distribution, lesser dose and lesser side-effects, which can theoretically prevent drug resistance. The aim of this treatment is "volume reduction" which is achieved later and stays longer even while the toxin effect is gone. This is in contrast to the desired "tension reduction" effect for dynamic facial muscle wrinkles which appears early and regresses early. ${ }^{[4]}$

The mechanism of botulinum toxin is to induce "disuse atrophy" in a muscle which may or may not be having the "overuse hypertrophy". As the effect of toxin weans off in balanced muscles (masseter), a "balanced recovery" can be predicted achieving symmetry which is one of the desired outcomes. The symmetric appearance of the face was the more important criteria for our patient satisfaction which can be achieved and can have an extended effect even at 24 months of followup. This validates the longer and extended "volume reduction" result of botulinum toxin in masseter muscle hypertrophy.

\section{Financial support and sponsorship}

Nil.

\section{Conflicts of interest}

There are no conflicts of interest.

\section{REFERENCES}

1. Kim NH, Chung JH, Park RH, Park JB. The use of botulinum toxin type $A$ in aesthetic mandibular contouring. Plast Reconstr Surg 2005; 115:919-30. 
2. Moore AP, Wood GD. The medical management of masseteric hypertrophy with botulinum toxin type $\mathrm{A}$. $\mathrm{Br} \mathrm{J}$ Oral Maxillofac Surg 1994; 32:26-8.

3. Rijsdijk BA, van ES RJ, Zonneveld FW, Steenks MH, Koole R. Botulinum toxin type A treatment of cosmetically disturbing masseteric hypertrophy. Ned Tijdschr Geneeskd 1998; 142:529-32.

4. Kim NH, Park RH, Park JB. Botulinum toxin type A for the treatment of hypertrophy of the masseter muscle. Plast Reconstr Surg 2010; 125:1693-705.
5. Choe SW, Cho WI, Lee CK, Seo SJ. Effects of botulinum toxin type A on contouring of the lower face. Dermatol Surg 2005; 31:502-7.

6. Xie Y, Zhou J, Li H, Cheng C, Herrler T, Li Q. Classification of masseter hypertrophy for tailored botulinum toxin type $A$ treatment. Plast Reconstr Surg 2014; 134:209-18.

7. Fedorowicz Z, van Zuuren EJ, Schoones J. Botulinum toxin for masseter hypertrophy. Cochrane Database Syst Rev 2013; 9:CD007510. 